Research Article

\title{
Study of clinical profile and certain modifiable risk factors associated with acute respiratory infection cases admitted in a tertiary care hospital
}

\author{
Jayashree D. Naik ${ }^{1}$, Swapnil R. Jain ${ }^{1}$, Madhuri P. Mathurkar ${ }^{1}$, Sandeep P. Suryawanshi ${ }^{2}$, \\ Sandesh V. Kamble', Sandeep D. Babar ${ }^{1}$
}

${ }^{1}$ Department of Community Medicine, Government Medical College, Miraj, Maharashtra- 416410, India

${ }^{2}$ Medical officer, District nucleus team, Assistant director health services, leprosy, Nashik, Maharashtra, India

Received: 13 October 2015

Accepted: 17 December 2015

\author{
*Correspondence: \\ Dr. Swapnil Jain, \\ E-mail: sjvicky85@gmail.com
}

Copyright: () the author(s), publisher and licensee Medip Academy. This is an open-access article distributed under the terms of the Creative Commons Attribution Non-Commercial License, which permits unrestricted non-commercial use, distribution, and reproduction in any medium, provided the original work is properly cited.

\begin{abstract}
Background: Childhood acute respiratory infection (ARI)/pneumonia is a significant public health problem in India, although robust epidemiological data is not available on its incidence. Mortality due to pneumonia accounts for approximately one-fourth of the total deaths in under five children, in India. The main aim is to assess clinical profile and associated risk factors of ARI cases admitted in tertiary care hospital.

Methods: A cross-sectional descriptive study conducted in a tertiary care hospital in Western Maharashtra, targeting all ARI cases admitted over a period of $1 \mathrm{yr}$. in the Pediatric ward at Govt. Medical College and Hospital, Miraj, India from 1 January 2011 to 31 December 2011. A pre- tested structured questionnaire with details regarding clinical picture and risk factors influencing outcome of ARI cases was used to collect the information from person accompanying ARI child preferably mother. Statistical software SPSS 16 for proportions, chi square test and odds ratio are used for statistical analysis.

Results: Out of 352 cases, tonsillar congestion was the most common sign (86.36\%) and cough was the most common presenting symptom (91.48\%). Majority (72.73\%) of ARI children had hospital stay for $<7$ days. Significant risk factors associated with outcome of ARI Cases were Breast feeding and Nutritional status of child.

Conclusions: Nutritional factors, malnutrition, and lack of breast-feeding constitute independent risk factors for pneumonia and interventions include efficient antenatal care, promotion of breast feeding, and appropriate $\mathrm{MCH}$ and family welfare services.
\end{abstract}

Keywords: ARI, Pneumonia, Breast feeding, Immunisation, Vitamin A, Malnutrition

\section{INTRODUCTION}

Acute respiratory infection (ARI) is an acute infection of any part of the respiratory tract and related structures including paranasal sinuses, middle ear and pleural cavity. It included all infections less than 30 days duration except those of the middle ear where the duration of an acute episode is less than 14 days. ${ }^{1}$ Globally on an average, children below five years of age suffer five episodes of ARI per child per year, thus accounting for about 238 million attacks. Consequently, ARIs are responsible for about $30-50 \%$ of visits to health facilities and about $20-40 \%$ of hospital admissions. ${ }^{2}$

ARI is one of the major causes of death. In India, Hospital records from high mortality states that upto $13 \%$ of inpatients deaths in paediatric wards are due to ARI. According to recent WHO/UNICEF data, about $20 \%$ of all deaths in children under 5 years are due to acute lower respiratory infections (pneumonia, bronchiolitis and 
bronchitis); $90 \%$ of these deaths are due to pneumonia. Studies have shown that up to $19 \%$ of children hospitalized with pneumonia die in India. ${ }^{3}$ As no such studies have been conducted in this area, this preliminary survey was conducted on to assess clinical profile and associated risk factors of ARI cases admitted in tertiary care hospital.

\section{METHODS}

A descriptive cross sectional, hospital based study conducted in Government Medical College and Hospital in Western Maharashtra over period of one calendar year from January 2011 to December 2011. It was part of project conducted under department of community medicine GMC, Miraj, Maharashtra, India. Prior permission from the institutional ethical committee was obtained and verbal informed consent was taken from person accompanying the ARI child; preferably the mothers were interviewed. Care was taken to avoid any duplication.

Acute respiratory tract infections were classified depending on whether they affect the upper or lower respiratory tract. The upper respiratory tract consists of the airways from the nostrils, to the vocal cords in the larynx, including the paranasal sinuses and middle ear. They include rhinitis, sinusitis, ear infections, acute pharyngitis or tonsillopharyngitis, epiglottitis, and laryngitis. Ear infections and pharyngitis cause the more severe complications. ${ }^{4}$ The lower respiratory tract covers the continuation of the airways from the trachea and bronchi to the bronchiole and alveoli. The most common lower respiratory tract infections are pneumonia, bronchitis and bronchiolitis. In the present study, the operational definition of an ARI episode used was based on a child having at least one of the following recognizable symptoms of ARI (cough, runny nose, ear discharge, and sore throat, which might be associated with fever, chest retractions, and fast breathing) within the last 2 weeks of the visit. ARI cases were classified according to WHO classification of severity of pneumonia. ${ }^{5}$ All cases of ARI admitted in Paediatrics ward at Govt. Medical College and Hospital were examined and interview of the person accompanying the child; preferably the mother, was taken on the same day. The information regarding the Socio-demographic factors and Environmental factors was recorded on predesigned, pretested, questionnaire. The association between outcome of ARI cases with socio-demographic characteristics and Environmental variables were studied. Statistical analysis was done by percentages, proportions, univariate analysis and Chi-square test.

\section{RESULTS}

Out of total 363 cases admitted in the hospital, 352 could be covered, interviewed and examined. The remaining 11 could not be included in the study due to various reasons viz. not willing to participate or non-cooperation of the caretakers or parents accompanying the child for interview and examination, discharged against medical advice/ discharged on request etc.

Table 1: Clinical profile of ARI cases $(n=352)$.

\begin{tabular}{|c|c|c|c|c|c|c|c|c|c|}
\hline \multirow{3}{*}{\multicolumn{2}{|c|}{ Clinical Features }} & \multicolumn{6}{|c|}{ Age Group } & \multirow{2}{*}{\multicolumn{2}{|c|}{ Total }} \\
\hline & & \multicolumn{2}{|c|}{$<1$ year } & \multicolumn{2}{|c|}{ 1-5 year } & \multicolumn{2}{|c|}{$>5$ year } & & \\
\hline & & No & $\%$ & No & $\%$ & No & $\%$ & \multirow{2}{*}{$\begin{array}{l}\text { No } \\
304\end{array}$} & \multirow{2}{*}{$\begin{array}{c}\% \\
86.36\end{array}$} \\
\hline \multirow[t]{6}{*}{ Signs ${ }^{*}$} & $\begin{array}{l}\text { Throat/Tonsil } \\
\text { congestion }\end{array}$ & 160 & 85.56 & 105 & 91.30 & 39 & 78.0 & & \\
\hline & Coryza & 145 & 77.54 & 97 & 84.35 & 39 & 78.0 & 281 & 79.83 \\
\hline & Crepitations & 112 & 59.89 & 61 & 53.04 & 25 & 50.0 & 198 & 56.25 \\
\hline & Rhonchi & 58 & 31.02 & 32 & 27.83 & 11 & 22.0 & 101 & 28.69 \\
\hline & Chest indrawing & 28 & 14.97 & 20 & 17.39 & 0 & 0.0 & 48 & 13.64 \\
\hline & Ear discharge & 14 & 7.49 & 12 & 10.4 & 5 & 10.0 & 31 & 8.81 \\
\hline \multirow[t]{5}{*}{ Symptoms ${ }^{*}$} & Cough & 164 & 87.70 & 110 & 95.65 & 48 & 96.0 & 322 & 91.48 \\
\hline & Fever & 156 & 83.42 & 95 & 82.61 & 36 & 72.0 & 287 & 81.53 \\
\hline & Cold/Running nose & 138 & 73.80 & 90 & 78.26 & 40 & 80.0 & 268 & 76.14 \\
\hline & Breathlessness & 107 & 57.22 & 59 & 51.30 & 20 & 40.0 & 186 & 52.84 \\
\hline & Unable to drink/feed & 10 & 5.35 & 8 & 6.96 & 2 & 4.0 & 20 & 5.68 \\
\hline
\end{tabular}

*Multiple responses. 
Table 2: Distribution of cases according to severity of ARI and its association with age (n=302).

\begin{tabular}{|c|c|c|c|c|c|c|c|c|c|c|}
\hline \multirow{2}{*}{ Age } & \multicolumn{8}{|c|}{ Severity of ARI } & \multirow{2}{*}{\multicolumn{2}{|c|}{ Total }} \\
\hline & \multicolumn{2}{|c|}{ Very severe disease } & \multicolumn{2}{|c|}{ Severe Pneumonia } & \multicolumn{2}{|c|}{ Pneumonia } & \multicolumn{2}{|c|}{ No pneumonia } & & \\
\hline$<1$ year & 15 & 68.18 & 28 & 58.33 & 116 & 67.44 & 28 & 46.67 & 187 & 61.92 \\
\hline 1-5 year & 7 & 31.82 & 20 & 41.67 & 56 & 32.56 & 32 & 53.33 & 115 & 38.08 \\
\hline Total & 22 & 100 & 48 & 100 & 172 & 100 & 60 & 100 & 302 & 100 \\
\hline
\end{tabular}

$\left(\chi^{2}=8.772 ; \mathrm{df}=3 ; \mathrm{p}=0.0325\right)$

Table 3: Distribution of cases according to duration of hospital stay.

\begin{tabular}{|c|c|c|c|c|c|c|c|c|}
\hline \multirow[t]{3}{*}{ Duration of hospital stay } & \multicolumn{6}{|c|}{ Age group } & \multirow{2}{*}{\multicolumn{2}{|c|}{ Total }} \\
\hline & \multicolumn{2}{|c|}{$<1$ year } & \multicolumn{2}{|c|}{ 1-5 year } & \multicolumn{2}{|c|}{$>5$ year } & & \\
\hline & No & $\%$ & No & $\%$ & No & $\%$ & No & $\%$ \\
\hline$<7$ days & 132 & 70.59 & 90 & 78.26 & 34 & 68.0 & 256 & 72.73 \\
\hline 8-14 days & 49 & 26.20 & 21 & 18.26 & 15 & 30.0 & 85 & 24.15 \\
\hline$\geq 15$ days & 06 & 3.21 & 04 & 3.48 & 01 & 2.0 & 11 & 3.12 \\
\hline Total & 187 & 100 & 115 & 100 & 50 & 100 & 352 & 100 \\
\hline
\end{tabular}

(Mean=5.84 days; $\mathrm{SD}=3.54 ;$ Mode $=6$ days; Median=6 days)

Table 4 : Association between duration of complaints before hospitalization with hospital stay in patients.

\begin{tabular}{|c|c|c|c|c|c|c|c|c|}
\hline \multirow{3}{*}{ Duration of hospital stay } & \multicolumn{6}{|c|}{ Duration of complaints before hospitalization } & \multirow{2}{*}{\multicolumn{2}{|c|}{ Total }} \\
\hline & \multicolumn{2}{|c|}{$\leq$ 4days } & \multicolumn{2}{|c|}{ 5-8 days } & \multicolumn{2}{|c|}{ >8days } & & \\
\hline & No & $\%$ & No & $\%$ & No & $\%$ & No & $\%$ \\
\hline$\leq 7$ days & 87 & 84.47 & 119 & 74.38 & 50 & 56.18 & 256 & 72.73 \\
\hline$>7$ days & 16 & 15.53 & 41 & 25.62 & 39 & 43.82 & 96 & 27.27 \\
\hline Total & 103 & 100 & 160 & 100 & 89 & 100 & 352 & 100 \\
\hline
\end{tabular}

$\left(\chi^{2}=19.66 ; \mathrm{df}=2 ; \mathrm{p}<0.001, \mathrm{HS}\right)$.

Table 5: Risk factors affecting outcome of ARI Cases.

\begin{tabular}{|c|c|c|c|c|c|c|c|c|}
\hline \multirow{3}{*}{ Risk factors } & & \multicolumn{6}{|c|}{ Number of cases } & \multirow[t]{3}{*}{ P value } \\
\hline & & \multicolumn{2}{|c|}{ Cured } & \multicolumn{2}{|c|}{ Deaths } & \multicolumn{2}{|c|}{ Total } & \\
\hline & & No & $\%$ & No & $\%$ & No & $\%$ & \\
\hline \multirow{3}{*}{ Breast feeding } & Not Exclusive breast feeding & 178 & 53.94 & 18 & 81.82 & 196 & 55.68 & \multirow{3}{*}{0.0383} \\
\hline & Exclusive breast feeding & 105 & 31.82 & 03 & 13.64 & 108 & 30.68 & \\
\hline & Still on breast feed & 47 & 14.24 & 01 & 4.54 & 48 & 13.64 & \\
\hline \multirow{2}{*}{$\begin{array}{l}\text { Nutritional } \\
\text { Status }\end{array}$} & Malnourished & 193 & 58.48 & 20 & 90.91 & 213 & 60.51 & \multirow{2}{*}{0.002} \\
\hline & Normal & 137 & 41.52 & 02 & 9.09 & 139 & 39.49 & \\
\hline \multirow{2}{*}{$\begin{array}{l}\text { Immunisation } \\
\text { Status }\end{array}$} & $\begin{array}{l}\text { Incomplete for age/ } \\
\text { Non immunised }\end{array}$ & 77 & 23.33 & 08 & 36.36 & 85 & 24.15 & \multirow{2}{*}{0.1669} \\
\hline & Complete for age & 253 & 76.67 & 14 & 63.64 & 267 & 75.85 & \\
\hline \multirow{4}{*}{$\begin{array}{l}\text { Vitamin A } \\
\text { Prophylaxis }\end{array}$} & Incomplete & 124 & 37.58 & 10 & 45.46 & 134 & 38.07 & \multirow{3}{*}{0.727} \\
\hline & Complete & 113 & 34.24 & 06 & 27.27 & 119 & 33.81 & \\
\hline & Not eligible & 93 & 28.18 & 06 & 27.27 & 99 & 28.12 & \\
\hline & Total & 330 & 100 & 22 & 100 & 352 & 100 & \\
\hline
\end{tabular}

Table 1 shows that tonsillar congestion was the most common sign $(86.36 \%)$, followed by coryza $(79.83 \%)$ while only $8.81 \%$ had ear discharge. Similarly cough was the most common presenting symptom (91.48\%) followed by fever (81.53), cold/running nose (76.14\%). Multiple responses were present. As there is no classification for severity of ARI for more than five years children, only 302 children less than 5 years of age were classified according to WHO classification. ${ }^{5}$ Out of 302 under five cases, $22(7.29 \%)$ as very severe disease, 48
(15.89\%) cases as severe pneumonia, 172 (56.95\%) cases as pneumonia. When severity of illness was considered with age, the difference was statistically significant (Table 2). Table 3 shows that majority $(72.73 \%$ ) children had hospital stay for $<7$ days. Statistically significant association was observed between the duration of complaints before hospitalization and duration of hospital stay (Table 4). 
Out of all risk factors studied, Breast feeding and nutritional status was found to be significantly associated while Immunization status and vitamin A prophylaxis were not significantly associated with outcome of ARI cases (Table 5). Out of total 22 deaths, majority i.e. $81.82 \%$ deaths were in the children who were not exclusively breast feed. Risk of death was $3.94 \%$ times higher among ARI cases that were not exclusively breast feed (oddsratio=3.94, Table 6). Among 22 deaths, majority i.e. $20(90.91 \%)$ deaths were in the children who were Malnourished. Malnourished cases showed risk of death 7.098 times than that of normally nourished cases (Table 6).

Table 6: Association of certain factors with outcome of ARI cases in decreasing order: Univariate Analysis.

\begin{tabular}{|llll|}
\hline Variable & $\begin{array}{l}\text { Odds } \\
\text { Ratio }\end{array}$ & $\begin{array}{l}\text { 95\% C.I for Odds } \\
\text { Ratio }\end{array}$ & \\
\cline { 2 - 4 } & Lower & Upper \\
\hline Nutritional status & 7.098 & 1.632 & 30.87 \\
\hline Breast feeding & 3.944 & 1.273 & 11.6 \\
\hline Immunisation & 1.878 & 0.7593 & 4.643 \\
\hline $\begin{array}{l}\text { Vitamin A } \\
\text { prophylaxis }\end{array}$ & 1.384 & 0.581 & 3.299 \\
\hline
\end{tabular}

\section{DISCUSSION}

With regard to clinical profile, cough was the most common presenting symptom, followed by fever and running nose. Findings corroborates with study conducted by Kumar V and Tambe MP et al, where cough was hallmark of ARI cases (in $100 \%$ cases). ${ }^{6,7}$ Since most of the cases irrespective of being in the group of URTI or LRTI, begins initially with URTI, so throat/tonsil congestion and coryza were the most common clinical finding. Examination in these patients showed variable inflamed and swollen nasal and pharyngeal membranes. These findings were comparable with previous study like Reddaiah VP et al, in which crepitations were present in $76 \%$ patients, rhonchi in $23.2 \%$ patients while chest indrawing was present in study by $26.4 \%$ patients of ARI. ${ }^{8}$

Out of 302 under five cases, majority i.e. 172 (56.95\%) cases were of pneumonia (Table 2). This may be due to majority of the cases reported within 8 days after initiation of complaints. Similar observation were present in study by Yousif TK et al, where majority of cases were of pneumonia (48.2\%). ${ }^{9}$ The median hospital stay was for 6 days, (Table 3) with the mean duration of $5.84 \pm 3.54$ days, comparable to study by Sahu SK et al, $(6.5 \pm 2.5$ days) and Ghazal SS et al, (6 days). ${ }^{10,11}$ Most of the patients had hospital stay for less than 7 days indicating that they responded well to the chemotherapy and hospital management. According to Table 4, it was observed that patients who reported late to the hospital or had complaints for a longer duration before hospitalization also had longer duration of hospital stay.
It was statistically highly significant. Possible reason may be that late reporting of cases without interventions increases the severity of the disease requiring more time for the recovery and thus increasing the severity of the disease requiring more time for the recovery and thus increasing the hospital stay.

\section{Risk factors affecting outcome of ARI Cases}

Present study shows that proportion of exclusively breast feeding is still very poor. It has to be increased. Lack of exclusively breast feeding was associated with poor outcome of ARI, similar to study by Mithrshahi S et al, risk of death was $3.94 \%$ times higher among ARI cases that were not exclusively breast feed (odds ratio $=3.94$, Table 6) which corroborates with findings by Arifeen $\mathrm{S}$ et al, $(\mathrm{OR}=2.40) .^{12,13}$ In developing countries, exclusively breast feed babies may also present better nutritional status in the first months of life, which may contribute to reduction in the incidence and severity of the infectious diseases. Prevalence of malnutrition was significantly associated with ARI cases consistent with previous study by Savitha MR et al, and Broor $\mathrm{S}$ et al. ${ }^{14,15}$ Malnutrition not only increases the frequency of ARI but also increases severity (mortality) due to ARI. In current study, majority $75.85 \%$ ARI cases were completely immunized for their age, resembling previous study by Savitha MR et al, in which $78.85 \%$ cases were fully immunized. $^{14}$ The direct association between immunization and ARI outcome could not be revealed statistically, might be due to the reason that in present study overall mortality among ARI cases was low compared to other studies. Statistically significant association between vitamin A prophylaxis and ARI was not found which is in contrast to study by Mitra NK, in which incomplete vitamin A prophylaxis was associated with ARI. ${ }^{16}$

\section{CONCLUSION}

Acute respiratory infections (ARI) range, in spectrum, from mild colds and coughs to life-threatening pneumonias. Among Children hospitalized with ARI, who had not received exclusive breast feeding and were malnourished had adverse outcome of disease resulting in more deaths. This study should stimulate further investigation of the relationship between above risk factors and outcome of ARI cases. There is good reason to believe that there should be a significant relationship. Also early reporting of ARI cases to hospital decreases severity of the disease due to medical intervention. These findings have important public health implications.

\section{Limitations}

As the present study was hospital based study, hospitalized cases may not be representative of all ARI cases in the community, also as the information was not obtained from cases but from the parents/care taker, there is possibility of incorrect, incomplete information. As the 
interrogation was in the hospital, domestic environment could not be assessed.

\section{ACKNOWLEDGEMENTS}

The authors would like to thank the staff of paediatric ward for cooperation in data collection process. The authors also thank the concerned families who participated in the study.

Funding: No funding sources Conflict of interest: None declared

Ethical approval: The study was approved by the Institutional Ethics Committee

\section{REFERENCES}

1. Kishore J. A dictionary of public health. $2^{\text {nd }}$ ed. Century Publications, New Delhi, India;2007.

2. WHO. Health situation in the South-East Asia region. World Health Organisation 1998-2000.

3. Narain JP. Epidemiology of acute respiratory infections. Indian J Paediatrics. 1987;54(2):153-60.

4. Wallace RB, Kohatsu N, Last JM, Maxcy-RosenauLast Public Health and Preventive Medicine. $15^{\text {th }}$ edition. New York: McGraw-Hill. 2008.

5. Park K. Park's textbook of preventive and social medicine, $22^{\text {nd }}$ ed. Banarsidas Bhanot Publishers, Jabalpur, India. 2013:103-4.

6. Kumar V. Epidemiological methods in acute respiratory infections. Indian J. Paediatrics. 1987;54:205-11.

7. Tambe MP, Shivaram C, Chandrashekhar Y. Acute respiratory infection in children a survey in the rural community.Indian J Med Sci. 1999;53:249-53.

8. Reddaiah VP, Kapoor SK. Acute respiratory infection in under five: Experience at comprehensive rural health services project hospital,Ballabgarh. Indian Journal of Community Medicine.1995;20(1):13-8.

9. Yousif TK, Khaleq BA. Epidemiology of Acute Respiratory Tract Infections (ARI) among Children Under Five Years Old Attending Tikirit General
Teaching Hospital. The Middle East Journal of Family Medicine. 2006;4(3):4-23.

10. Sahu SK, Sathapathy DM, Sahu T, Tripathy RM,Das BC,Pradhan S. A study of acute respiratory infection cases admitted to a tertiary level health centre. Health and Population-Perspectives and Issues. 2002;25(4):186-95.

11. Ghazal SS, Chowdhary D. Acute respiratory tract infections: epidemiological data, guided case management and outcome in a paediatric hospital in Riyadh. Annals of Saudi Medicine. 1998;18(1):758.

12. Mihrshahi S, Ichikawa N, Shuaib M, Wendy OW, Ampon R, Dibley MJ, et al. Prevalence of exclusive breast feeding in Bangladesh and its association with Diarrhoea and Acute Respiratory Infection. Results of the multiple Indicator cluster survey 2003.J Health Popul Nutr. 2007;25(2):195-204.

13. Arifeen S, Black RE, Antelman G, Baqui A, Caulfield L, Becker S. Exclusive breast feeding reduces Acute Respiratory Infection and diarrhoea deaths among infants in Dhaka slums. Paediatrics. 2001;108(4):67-75.

14. Savitha MR, Nandeeshwara SB, Pradeep Kumar MJ, ul-Haque F, Raju CK. Modifiable Risk factors for Acute lower Respiratory Infection. Indian Journal of Paediatrics. 2007;74:477-81.

15. Broor S, Pandey RM, Ghosh M, Maitrry RS, Lodha $\mathrm{R}$,Singhal T, et al. Risk factors for severe Acute lower Respiratory Tract infection in under five children. Indian Journal of paediatrics. 2001;38(12):1361-8.

16. Mitra NK. A longitudinal study on ARI among rural under-fives. Indian Journal of Community Medicne. 2001;26(1):8-11.

Cite this article as: Naik JD, Jain SR, Mathurkar MP, Suryawanshi SP, Kamble SV, Babar SD.

Study of clinical profile and certain modifiable risk factors associated with acute respiratory infection (ARI) cases admitted in a tertiary care hospital. Int J Contemp Pediatr 2016;3:129-33. 